\title{
Effect of Afghan Hibiscus sabdariffa L. and Carum Carvi L. Hydro-alcoholic Extracts Either Alone or in Combination on Blood Glucose Level in Diabetic Rats
}

\author{
Research Article
}

\section{Murtaza Haidari1, Kawsar Alami1, Arefa Hossaini1, Sayed Yousof Mousavi*}

1. Research and Technology Center, Khatam Al-Nabieen University, Kabul, Afghanistan. 2. Assistant professor, Department of physiology, Khatam Al-Nabieen University, Kabul, Afghanistan.

\begin{abstract}
Combination therapy is considered as a new and effective therapeutic strategy for control of hyperglycemia. The present study aimed to determine the hypoglycemic effect of Afghan Hibiscus sabdariffa L. and Carum Carvi L. hydro-alcoholic extracts either alone or in combination on diabetic rats. Streptozotocin-induced diabetic rats were administered intraperitoneally with hydro-alcoholic extracts of $H$. sabdariffa $(75,150$ and $300 \mathrm{mg} / \mathrm{kg})$, C. carvi $(150$, 300 and $500 \mathrm{mg} / \mathrm{kg}$ ) and their combinations for 21 days. The Fasting blood glucose and body weight of rats were determined on $0,7,14$ and $21^{\text {st }}$ days. The results showed a significant $(\mathrm{P}<0.0001)$ hypoglycemic effect of $H$. sabdariffa extract $(75,150$ and $300 \mathrm{mg} / \mathrm{kg})$ on 7,14 and $21^{\text {th }}$ days, C. carvi extract $(500 \mathrm{mg} / \mathrm{kg})$, and their effective doses combination (75:25), especially on $7^{\text {th }}$ day. Only $75 \mathrm{mg} / \mathrm{kg}$ of $H$. sabdariffa had positive effect on body weight loss of diabetic rats $(\mathrm{P}<0.05)$. One can conclude that Afghan H. sabdariffa and C. carvi hydro-alcoholic extracts and their combination have a hypoglycemic effect. However, their combinations do not have any synergic effects, so the hypoglycemic effect of $H$. sabdariffa was much greater and even normalized the blood glucose level.
\end{abstract}

Key Words: Afghanistan, Hibiscus sabdariffa, Carum carvi, Combination, Blood glucose level.

\section{Introduction}

Diabetes mellitus is the most common endocrine disorder, which considered as one of the main causes of death and disability in many countries (1). This disorder, which is known as the silent epidemic of the present century, affects many people in the world and its prevalence is increasing. According to the International Diabetes Federation's (IDF) report, in 2017 there were 451 million people with diabetes worldwide and it is expected that this value will increase to 693 million by 2045 (2). Diabetes mellitus is a group of metabolic diseases, characterized by hyperglycemia as a result of defects in insulin secretion, insulin function, or both (3). The main cause of diabetic mortality and morbidity is diabetic complications, which resulted from hyperglycemia (4). Therefore, the major target of medicinal therapy for diabetes is balancing blood glucose level (5).

There are multiple medicinal plants which have benefits on diabetes, especially on hyperglycemia, due to their effective constituents (4). In traditional medicine, the use of herbs combinations is recommended, because it is approved that the combination of multiple herbs has more effects than

* Corresponding Author:

Sayed Yousof Mousavi

Assistant Professor,

Department of Physiology,

Khatam Al-Nabieen University, $1^{\text {st }}$ street of Karte 4,

Kabul, Afghanistan.

Email Id: mousavi.knurtc@knu.edu.af individual herbs (6). Studies also have been shown that combination therapy is considered as a new and effective therapeutic strategy for control of hyperglycemia (4).

One of the medicinal herbs, which have effective constituents, is Hibiscus sabdariffa $L$. ( $H$. sabdariffa) that belongs to Malvacea family. $\mathrm{H}$. Sabdariffa has multiple active constituents such as organic acids, anthocyanins, polysaccharides, and flavonoids $(7,8)$. Its petals also contain protein, lipid, carbohydrates, different minerals, and vitamins $(8,9)$. Multiple studies have shown that $\mathrm{H}$. sabdariffa has positive effects on different aspects of diabetes treatment, including reduction of fasting blood glucose (FBG) and postprandial glucose, improvements of glucose tolerance and insulin sensitivity (10), and inhibition of alpha-glucosidase and alpha-amylase enzymes (11).

Also, Carum carvi (C. Carvi) is another medicinal plant which belongs to Apaiceae family (12, 13). The main constituents of $C$. carvi are flavonoids (quercetin, kaempferol), monoterpenes (carvon, limonen and timol) and glycosides (carol and dihydrocarol) (14-16). There are multiple studies which show the positive effects of $C$. carvi extract on blood glucose level of diabetic rats $(17,18)$.

However, because of the impact of climate and geographical conditions on the quality of plants (19), as well as most effectiveness of herbs combinations on the treatment of hyperglycemia $(4,6)$, this study determines the hypoglycemic effects of Afghan $H$. sabdariffa and C. carvi hydro-alcoholic extracts effective doses, either alone or in combination on diabetic rats. 


\section{Materials and Methods}

\section{Animals}

Sixty-six adult Sprague-Dawley male rats weighing between 180 and $200 \mathrm{~g}$, randomly selected from Khatam Al-Nabieen University Research and Technology Center (KNURTC), were housed in Plexyglass cages with free access to food and water. Animals were kept under stable room temperature $\left(23 \pm 2^{\circ} \mathrm{C}\right)$ and a 12 hours light/dark cycle (the light period started at 7 a.m.). The experimental protocol related to animal's use has complied with all the relevant national regulations and institutional policies, so approved by the ethic research board of Khatam Al-Nabieen University and were conducted following the ethical guidelines set by the $8^{\text {th }}$ edition of National Institute of Health $(\mathrm{NIH})$ guide for the care and use of laboratory animals. Rats were carefully handled to minimize unwanted stress during housing and experiments.

\section{Preparation of extract}

The petals of $H$. sabdariffa from Asmar, Kunar province and seeds of $C$. carvi from Behsood, Maidan Wardak province of Afghanistan, were collected freshly. Then, plants were dried in the shade, at room temperature and then powdered. $100 \mathrm{~g}$ of $H$. sabdariffa petals and $200 \mathrm{~g}$ of $C$. carvi were macerated individually with $70 \%$ ethanol (1:4) and kept for 72 hours at room temperature, with occasional shaking. After 72 hours, the mixtures were filtered and evaporated at room temperature (20).

\section{Induction of experimental diabetes}

The experimental diabetes was induced by a single intraperitoneal (i.p.) administration of streptozotocin (STZ) (Sigma-Aldrich, USA), at a dose of $55 \mathrm{mg} / \mathrm{kg}$ after 8 hours fasting. The STZ was dissolved in $0.1 \mathrm{M}$ citrate buffer. 72 hours later, diabetes was confirmed by determining the FBG level. The rats with $200 \mathrm{mg} / \mathrm{dl}$ FBG level were only considered for the experiment.

\section{Experimental groups}

Rats were divided into 11 groups $(n=6)$ :

Group I (Normal), Rats of this group received Normal saline (1 ml, i.p.) for 21 days;

Group II (Diabetic), Rats of this group became diabetic and received Normal saline $(1 \mathrm{ml}$, i.p.) for 21 days;

Group III-V (H. sabdariffa 75, 150, $300 \mathrm{mg} / \mathrm{kg}$ ), Diabetic rats received $H$. sabdariffa hydro-alcoholic extract $(75,150$ and $300 \mathrm{mg} / \mathrm{kg}$, respectively, i.p.) for 21 days;

Group VI-VIII (C. carvi 150, 300, $500 \mathrm{mg} / \mathrm{kg}$ ), Diabetic rats received $C$. carvi hydro-alcoholic extract $(150,300$ and $500 \mathrm{mg} / \mathrm{kg}$, respectively, i.p.) for 21 days;
Group IX (Combination 1), Diabetic rats received combination $(75: 25)$ of $H$. sabdariffa $(56.25 \mathrm{mg} / \mathrm{kg})$ and C. carvi $(125 \mathrm{mg} / \mathrm{kg})$ hydro-alcoholic extracts by i.p. administration for 21 days;

Group X (Combination 2), Diabetic rats received combination (50:50) of $H$. sabdariffa $(37.5 \mathrm{mg} / \mathrm{kg})$ and C. carvi $(250 \mathrm{mg} / \mathrm{kg})$ hydro-alcoholic extracts by i.p. administration for 21 days;

Group XI (Combination 3), Diabetic rats received combination (25:75) of $H$. sabdariffa $(18.75 \mathrm{mg} / \mathrm{kg})$ and C. carvi $(375 \mathrm{mg} / \mathrm{kg})$ hydro-alcoholic extracts by i.p. administration for 21 days.

FBG level Measurement. The FBG levels of all rats were measured after 8 hours fasting, by blood withdrawn from the tail of rats using strips and glucometer (ACCU Check Active - Roche ${ }^{\mathrm{TM}}$ ) on 0,7 , 14 and 21 days (considering after 3 days of STZ administration).

Body weight determination. The body weight of all rats was determined on 0,7,14 and 21 days.

Statistical analysis. The statistical analysis was done with Graph pad prism (6.07) software. The FBG levels were analyzed by Two-way ANOVA, followed by Dunnets test multiple comparisons. Difference between body weight of different groups was analyzed by nonparametric Kruskal Wallis test. The difference amongst means was considered statistically significant if the $\mathrm{P}<0.05$. The results are expressed as mean $\pm \mathrm{SEM}$.

\section{Results}

\section{FBG level measurement}

The FBG level of all groups was measured on $0,7,14$ and $21^{\text {st }}$ days. There was a significant difference in the level of FBG among normal and diabetic groups $(\mathrm{P}<0.0001)$. The FBG level was significantly decreased in H. sabdariffa 75, 150 and $300 \mathrm{mg} / \mathrm{kg}$ groups as compared with diabetic group on 7,14 and $21^{\text {th }}$ days $(\mathrm{P}<0.0001)$ (Figure 1). In addition, the effect of $C$. carvi different doses was evaluated on the FBG level (Figure 2 ). The difference in the level of FBG only between $C$. carvi $500 \mathrm{mg} / \mathrm{kg}$ and the diabetic group was significant, on 7, 14 and $21^{\text {st }}$ days, and especially on $7^{\text {th }}$ day $(\mathrm{P}<0.0001)$. The FBG level was not significantly decreased in 150 and $300 \mathrm{mg} / \mathrm{kg}$ groups. As a result, the $75 \mathrm{mg} / \mathrm{kg}$ of $H$. sabdariffa and $500 \mathrm{mg} / \mathrm{kg}$ of $C$. carvi hydro-alcoholic extracts were considered as effective doses, combined in different proportions and their hypoglycemic effect was evaluated (Figure 3). The FBG level is significantly decreased only in Combination 1 group, as compared with the diabetic group on day 7 $(\mathrm{P}<0.0001)$. There was no significant difference in the FBG level between combination 2 and 3 and the diabetic group $(\mathrm{P}>0.05)$. 


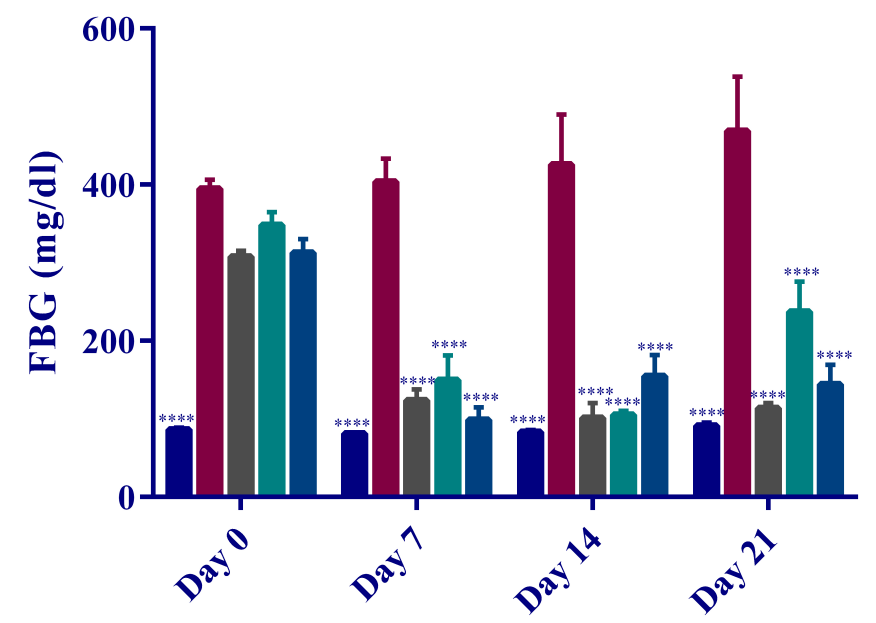

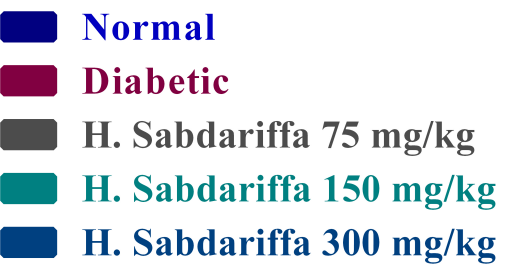

Normal

Diabetic

H. Sabdariffa $75 \mathrm{mg} / \mathrm{kg}$

H. Sabdariffa $300 \mathrm{mg} / \mathrm{kg}$

Figure 1. The effect of $H$. sabdariffa $(75,150$ and $300 \mathrm{mg} / \mathrm{kg})$ hydro-alcoholic extract on FBG level of diabetic rats. Data are shown as Mean \pm SEM. FBG, fasting blood glucose. ${ }^{* * * *}: \mathbf{P}<0.0001$ as compared with diabetic group.

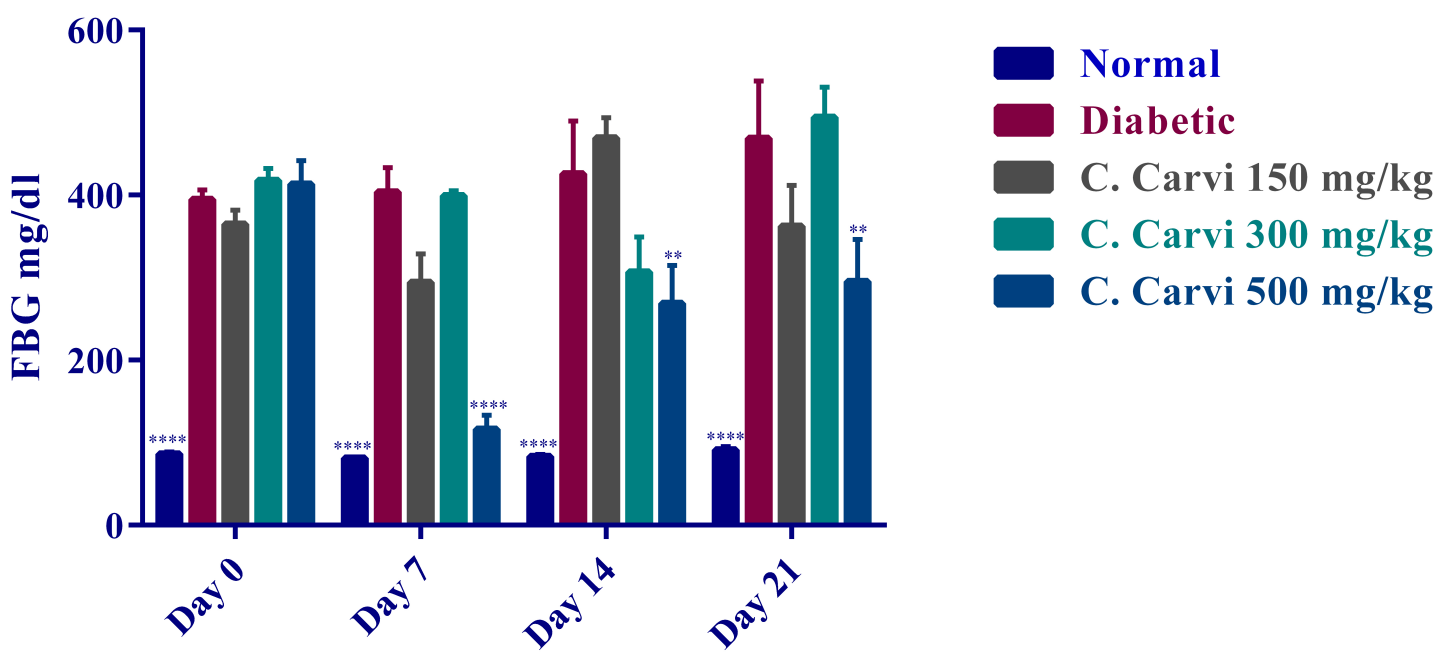

Figure 2. The effect of $C$. carvi $(150,300$ and $500 \mathrm{mg} / \mathrm{kg})$ hydro-alcoholic extract on FBG level of diabetic rats. Data are shown as Mean \pm SEM. FBG, fasting blood glucose. ${ }^{* *}: \mathrm{P}<0.01,{ }^{* * * *}: \mathrm{P}<0.0001$ as compared with diabetic group.

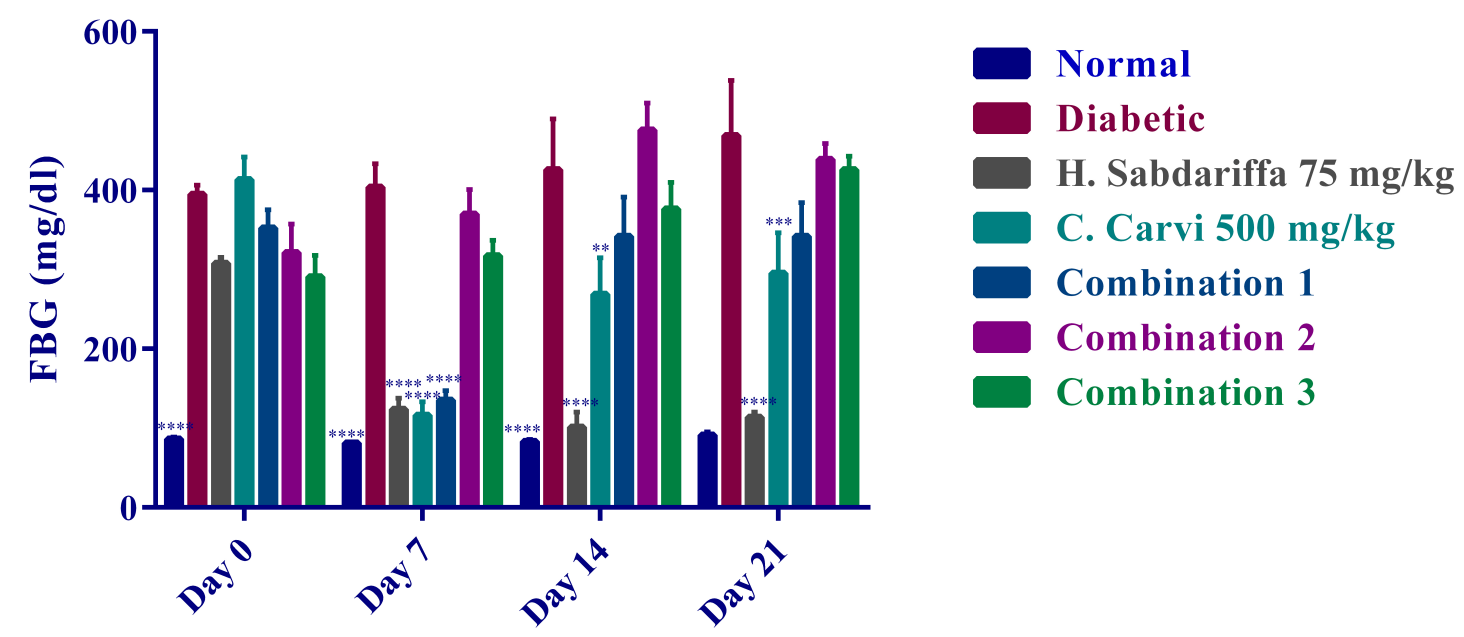

Figure 3. The effect of $\boldsymbol{H}$. sabdariffa and $\boldsymbol{C}$. carvi hydro-alcoholic extracts combinations on FBG level of diabetic rats. Data are shown as Mean \pm SEM. FBG, fasting blood glucose. ${ }^{* *}: P<0.01,{ }^{* * *}: P<0.001,{ }^{* * * *}: P<0.0001$ as compared with diabetic group. 


\section{Body weight determination}

The body weight of all groups was determined on $0,7,14$ and $21^{\text {th }}$ days. There was a significant body weight loss in a diabetic group as compared with the normal group $(\mathrm{P}<0.001)$. The body weight was significantly increased only in $H$. sabdariffa $75 \mathrm{mg} / \mathrm{kg}$ group as compared with the diabetic group $(\mathrm{P}<0.01)$. However, there was not a significant difference in the body weight among $H$. sabdariffa $150,300 \mathrm{mg} / \mathrm{kg}, C$. carvi $150,300,500 \mathrm{mg} / \mathrm{kg}$, combination 1,2 and 3 groups and diabetic group $(\mathrm{P}>0.05)$ (Table 1).

Table 1. The body weight of different groups

\begin{tabular}{|c|c|c|c|c|c|}
\hline \multirow{2}{*}{ Groups } & \multicolumn{4}{|c|}{ Body weight (g) } & Weight gain/lost \\
\hline & Day 0 & Day 7 & Day 14 & Day 21 & Day 0-21 \\
\hline Normal & $181.50 \pm 0.62$ & $185.83 \pm 0.48$ & $201.50 \pm 1.78$ & $208.50 \pm 1.18$ & $27.00 \pm 1.37^{* *}$ \\
\hline Diabetic & $165.67 \pm 0.88$ & $170.50 \pm 4.14$ & $158.00 \pm 02.25$ & $155.83 \pm 2.24$ & $-9.83 \pm 2.45$ \\
\hline H. sabdariffa $75 \mathrm{mg} / \mathrm{kg}$ & $177.67 \pm 0.80$ & $179.50 \pm 4.10$ & $188.83 \pm 0.75$ & $198.33 \pm 2.82$ & $20.67 \pm 3.08^{*}$ \\
\hline H. sabdariffa $150 \mathrm{mg} / \mathrm{kg}$ & $171.83 \pm 1.99$ & $174.33 \pm 3.40$ & $173.17 \pm 4.01$ & $179.00 \pm 5.44$ & $7.17 \pm 6.08$ \\
\hline H. sabdariffa $300 \mathrm{mg} / \mathrm{kg}$ & $176.83 \pm 1.85$ & $170.0 \pm 2.57$ & $170.83 \pm 4.40$ & $175.83 \pm 6.31$ & $-1.00 \pm 4.97$ \\
\hline C. carvi $150 \mathrm{mg} / \mathrm{kg}$ & $165.8 \pm 2.06$ & $157.0 \pm 2.28$ & $150.2 \pm 2.87$ & $137.2 \pm 2.60$ & $-28.67 \pm 1.43$ \\
\hline C. carvi $300 \mathrm{mg} / \mathrm{kg}$ & $164.8 \pm 1.85$ & $160.70 \pm 3.95$ & $155.30 \pm 2.72$ & $148.70 \pm 3.15$ & $-16.67 \pm 2.51$ \\
\hline C. carvi $500 \mathrm{mg} / \mathrm{kg}$ & $176.20 \pm 2.81$ & $161.3 \pm 2.36$ & $160.70 \pm 2.78$ & $163.0 \pm 3.25$ & $-11.67 \pm 2.50$ \\
\hline Combination 1 & $175.0 \pm 5.12$ & $170.50 \pm 4.82$ & $171.50 \pm 3.57$ & $181.50 \pm 4.31$ & $6.50 \pm 5.40$ \\
\hline Combination 2 & $181.20 \pm 2.53$ & $185.0 \pm 1.51$ & $179.80 \pm 2.47$ & $182.8 \pm 2.86$ & $-0.67 \pm 1.75$ \\
\hline Combination 3 & $192.30 \pm 2.75$ & $192.0 \pm 3.26$ & $185.30 \pm 2.33$ & $185.70 \pm 2.50$ & $-6.67 \pm 3.0$ \\
\hline
\end{tabular}

Data are shown as Mean \pm SEM. ${ }^{*}: \mathrm{P}<0.05,{ }^{* *}: \mathrm{P}<0.01$ as compared with the diabetic group.

\section{Discussion}

In this study, the effect of $H$. sabdariffa and $C$. carvi hydro-alcoholic extracts either alone or in combination on the FBG level of STZ-induced diabetic rats was evaluated. STZ is a toxic, diabetogenic compound, which inhibits insulin secretion and induces insulin-dependent diabetes (21). This compound causes pancreatic beta cells necrosis through the oxidative stress pathway (21-23). Administration of STZ in animals leads to an increase in blood glucose level and a decrease in body weight $(22,24)$.

Similarly, this study showed that a single i.p. administration of STZ increased the FBG level and decreased body weight in a diabetic group as compared with the normal group. So, we can conclude that STZ in this study could develop experimental diabetes model.

Besides, i.p. administration of $H$. sabdariffa hydro-alcoholic extract $(75,150$ and $300 \mathrm{mg} / \mathrm{kg}$ ) for 21 days could decrease the FBG level significantly. However, only $75 \mathrm{mg} / \mathrm{kg}$ of $H$. sabdariffa extract could significantly increase the body weight of rats. This shown that Afghan $H$. sabdariffa hydro-alcoholic extract has a hypoglycemic effect and its effective dose for reducing the FBG level and compensating the body weight loss of diabetic rats is $75 \mathrm{mg} / \mathrm{kg}$.

Similarly, previous studies showed that $H$. sabdariffa can decrease the FBG level in diabetic rats and confirm the results of this study. For instance, in one study, the effect of oral administration of $H$. sabdariffa ethanolic extract in 1.0 and $0.1 \mathrm{~g} / \mathrm{kg}$ doses for 6 weeks on blood glucose level and insulin secretion rate in normal and diabetic rats was evaluated. The results have shown that only $1.0 \mathrm{~g} / \mathrm{kg}$ dose of the extract could decrease the blood glucose level in diabetic rats, not in normal rats. The extract increased the number of pancreatic islets. They concluded that the antidiabetic activity of $H$. sabdariffa extract may be partially mediated by its stimulating effect on insulin secretion (10). Also, another study was evaluated the effect of $H$. sabdariffa polyphenolic extract on hyperglycemia, hyperlipidemia and glycation-oxidative stress and insulin resistance in type 2 diabetic rats. They showed that oral treatment with $H$. sabdariffa hydro-alcoholic extract reduced hyperglycemia, hyperlipidemia and glycation-oxidative stress and improved insulin resistance, especially at the dose of $200 \mathrm{mg} / \mathrm{kg}$ (25). In summary, different studies have been shown that the possible mechanism of the effect of $H$. sabdariffa extract on blood glucose level may be the increase of basal insulin level or induction of insulin secretion by pancreatic beta cells, as a result of an increase in the number of beta cells, as well as the increase in blood glucose transport into peripheral tissues. Also, these studies are emphasizing on the potent anti-oxidant constituents of $H$. sabdariffa which are protecting the pancreatic beta cells from destruction by STZ and actions of free radicals $(7,10,26,27)$.

In addition, the present study was shown that the i.p. administration of $C$. carvi hydro-alcoholic extract for 21 days could decrease the FBG level significantly. However, $500 \mathrm{mg} / \mathrm{kg}$ was the only effective dose for reducing the FBG level. Its effect was much better on $7^{\text {th }}$ day. So, we can conclude that the Afghan $H$. sabdariffa hydro-alcoholic extract can decrease the FBG level effectively, especially at highdose and short-term period of administration.

Previous studies have also confirmed the results of this study. A study evaluated the antidiabetic effect of C. carvi ethanolic extract on blood glucose level of normal and diabetic rats. They administrated $C$. carvi ethanolic extract at $0.1,0.2,0.4$ and $0.6 \mathrm{~g} / \mathrm{kg}$, i.p., and then measured the blood glucose level of rats 1, 3 and 5 hours after extract administration. Their results showed 
that $0.2,0.4$ and 0.6 doses of extracts could significantly decrease the blood glucose level and the insulin level in diabetic rats in 3 and 5 hours, but not in normal rats (17). Similarly, another study was evaluated the effect of $C$. carvi aqueous extract on body weight, serum blood glucose, and blood lipids in diabetic rats after feeding $1 \mathrm{~g} / \mathrm{kg}$ dose of extract for 21 days. They have been shown that aqueous extract of $C$. carvi could decrease the blood glucose level, total cholesterol and LDL, and increase the body weight (18). Also, another study showed that after a single dose or 14 daily doses of the C. carvi aqueous extract $(20 \mathrm{mg} / \mathrm{kg})$ oral administration, a significant decrease in blood glucose levels of diabetic rats was produced. Also, there was no significant effect on basal plasma insulin concentrations in either normal or diabetic rats, so they concluded that the underlying mechanism of this pharmacological activity seems to be independent of insulin secretion (16). Based on these results, it assumed that C. carvi inhibits hepatic glucose production, and stimulates glucose utilization by peripheral tissues, and its hypoglycemic effects are independent of insulin secretion. Also, it can act as an inhibitor of renal glucose reabsorption and intestinal glucose absorption. These all beneficial effects of C. carvi may be related to its main anti-oxidant constituents (16-18).

After determining the effective doses of Afghan $H$. sabdariffa and C. carvi hydro-alcoholic extracts on FBG level, the effect of the combination of their effective doses in different proportions on FBG level of diabetic rats, was evaluated. The results showed that only 75:25 combination of $H$. sabdariffa and $C$. carvi effective doses were significantly decreased the FBG level in diabetic rats, especially on $7^{\text {th }}$ day, and even normalized. However, as we compare the effect of these individual extracts with combinations of them, one can simply conclude that the effect of individual extracts on the FBG level is much greater than their combinations. Especially important, all doses of $H$. sabdariffa hydroalcoholic extract which used in this study, could normalize the FBG level in diabetic rats. As a result, Afghan $H$. sabdariffa hydro-alcoholic extract has higher hypoglycemic activity, as compared with $C$. carvi hydro-alcoholic extract and also with different proportions of their combinations. Also, despite the multiple different constituents and different hypoglycemic action mechanisms of $H$. sabdariffa (insulin-dependent) and $C$. carvi (non-insulin dependent) extracts, they don't have any synergic effects on the reduction of FBG level in diabetic rats.

\section{Conclusion}

In summary, one can conclude that Afghan $H$. sabdariffa and $C$. carvi hydro-alcoholic extracts and their combination (75:50) have a hypoglycemic effect. However, despite the multiple different constituents and different hypoglycemic action mechanisms, their combinations do not have any synergic effects, so the hypoglycemic effect of $H$. sabdariffa was much greater and even normalized.

\section{Acknowledgements}

This work is supported by the research and technology center of Khatam Al-Nabieen University Kabul, Afghanistan. We thank all officials for their valuable support for providing the equipment and facilities for this study.

\section{References}

1. Patel DK, Prasad SK, Kumar R, Hemalatha S, An overview on antidiabetic medicinal plants having insulin mimetic property. Asian. Pac. J. Trop. Biomed. 2012; 2: 320-330. https://doi.org/10.1016/ S2221-1691(12)60032-X

2. Cho N, Shaw JE, Karuranga S, Huang Y, da Rocha Fernandes JD, Ohlrogge AW, Malanda B, IDF Diabetes Atlas: Global estimates of diabetes prevalence for 2017 and projections for 2045. Diabetes. Res. Clin. Pract. 2018; 138: 271-281. https://doi.org/10.1016/j.diabres.2018.02.023

3. American Diabetes Association, Diagnosis and classification of diabetes mellitus. Diabetes. Care. 2010; 33(Supplement 1): S62-69. https://doi.org/ 10.2337/dc09-S062

4. Prabhakar PK, Kumar A, Doble M, Combination therapy: a new strategy to manage diabetes and its complications. Phytomedicine. 2014; 21: 123-130. https://doi.org/10.1016/j.phymed.2013.08.020

5. Patel DK, Kumar R, Laloo D, Hemalatha S, Natural medicines from plant source used for therapy of diabetes mellitus: An overview of its pharmacological aspects. Asian. Pac. Trop. Dis. 2012; 2: 239-250. https://doi.org/10.1016/ S2222-1808(12)60054-1

6. Ogbonnia SO, Odimegwu JI, Enwuru VN, Evaluation of hypoglycaemic and hypolipidaemic effects of aqueous ethanolic extracts of Treculia africana Decne and Bryophyllum pinnatum Lam. and their mixture on streptozotocin (STZ)-induced diabetic rats. Afr. J. Biotechnol. 2008; 7: 2535-2539.

7. Da-Costa-Rocha I, Bonnlaender B, Sievers H, Pischel I, Heinrich M, Hibiscus sabdariffa L.-A phytochemical and pharmacological review. Food. Chem. 2014; 165: 424-443. https://doi.org/10.1016/ j.foodchem.2014.05.002

8. Riaz G, Chopra R, A review on phytochemistry and therapeutic uses of Hibiscus sabdariffa L. Biomed. Pharmacother. 2018; 102: 575-586. https://doi.org/ 10.1016/j.biopha.2018.03.023

9. Carvajal-Zarrabal O, Barradas-Dermitz DM, OrtaFlores Z, Hayward-Jones PM, Nolasco-Hipólito C, Aguilar-Uscanga MG, Miranda-Medina A, Bujang $\mathrm{KB}$, Hibiscus sabdariffa L., roselle calyx, from ethnobotany to pharmacology. J. Exp. Pharmacol. 2012; 4: 25. https://doi.org/10.2147/JEP.S27974

10. Wisetmuen E, Pannangpetch P, Kongyingyoes B, Kukongviriyapan U, Yutanawiboonchai W, Itharat A, Insulin secretion enhancing activity of roselle calyx extract in normal and streptozotocin-induced diabetic rats. Pharmacogn. Res. 2013; 5: 65. https:// doi.org/10.4103/0974-8490.110520 
Sayed Yousof Mousavi et.al., Effect of Afghan Hibiscus sabdariffa L. and Carum Carvi L. on blood glucose level in diabetic rats

11. Ademiluyi AO, Oboh G. Aqueous extracts of Roselle (Hibiscus sabdariffa Linn.) varieties inhibit $\alpha$-amylase and $\alpha$-glucosidase activities in vitro. $\mathrm{J}$. Med. Food. 2013; 16(1): 88-93. https://doi.org/ 10.1089/jmf.2012.0004

12. Thippeswamy NB, Naidu KA, Achur RN, Antioxidant and antibacterial properties of phenolic extract from Carum carvi L. J. Pharm. Res. 2013; 7 : 352-357. https://doi.org/10.1016/j.jopr.2013.03.028

13. Showraki A, Emamghoreishi M, Oftadegan S, Anticonvulsant effect of the aqueous extract and essential oil of Carum carvi L. seeds in a pentylenetetrazol model of seizure in mice. Iran. J. Med. Sci. 2016; 41: 200.

14. Erjaee H, Rajaian $H$, Nazifi $S$, Chahardahcherik M, The effect of caraway (Carum carvi L.) on the blood antioxidant enzymes and lipid peroxidation in streptozotocin-induced diabetic rats. Comp. Clin. Path. 2015; 24: 1197-1203. https://doi.org/10.1007/ s00580-014-2060-1

15. Mahboubi M, Caraway as Important Medicinal Plants in Management of Diseases. Nat. Products. Bioprospect. 2019; 9: 1-11. https://doi.org/10.1007/ s13659-018-0190-x

16. Eddouks M, Lemhadri A, Michel JB, Caraway and caper: potential anti-hyperglycaemic plants in diabetic rats. J. Ethnopharmacol. 2004; 94: 143-148. https://doi.org/10.1016/j.jep.2004.05.006

17. Eidi A, Eidi M, Haeri Rohani A, Basati F, Hypoglycemic effect of ethanolic extract of Carum carvi L. seeds in normal and streptozotocin-induced diabetic rats. J. Med. Plant. 2010; 3: 106-113.

18. Haidari F, Seyed-Sadjadi N, Taha-Jalali M, Mohammed-Shahi $M$, The effect of oral administration of Carum carvi on weight, serum glucose, and lipid profile in streptozotocin-induced diabetic rats. Saudi. Med. J. 2011; 32: 695-700.

19. Astaf'eva OV, Sukhenko LT, Comparative analysis of antibacterial properties and chemical composition of Glycyrrhiza glabra L. from Astrakhan region (Russia) and Calabria region (Italy). Bull. Exp. Biol. Med. 2014; 156: 829-832. https://doi.org/10.1007/s10517-014-2462-8
20. Kooti W, Ghasemiboroon M, Ghafourian Boroujerdnia M, Asadi-Samani M, Harizi M, Sharafi-Ahvazi N, Afrisham R, The effects of celery leave extract on male hormones in rats. J. HerbMed. Pharmacol. 2015; 4: 56-60.

21. Lenzen S, The mechanisms of alloxan-and streptozotocin-induced diabetes. Diabetologia. 2008; 51: 216-226. https://doi.org/10.1007/ s00125-007-0886-7

22. Eleazu CO, Eleazu KC, Chukwuma S, Essien UN, Review of the mechanism of cell death resulting from streptozotocin challenge in experimental animals, its practical use and potential risk to humans. J. Diabetes. Metab. Disord. 2013; 12: 60. https://doi.org/10.1186/2251-6581-12-60

23. Szkudelski T, The mechanism of alloxan and streptozotocin action in B cells of the rat pancreas. Physiol. Res. 2001; 50: 537-546.

24. Deeds MC, Anderson JM, Armstrong AS, Gastineau DA, Hiddinga HJ, Jahangir A, Eberhardt NL, Kudva YC, Single dose streptozotocin-induced diabetes: considerations for study design in islet transplantation models. Lab. Anim. 2011; 45: 131-140. https://doi.org/10.1258/1a.2010.010090

25. Peng $\mathrm{CH}$, Chyau CC, Chan KC, Chan TH, Wang CJ, Huang CN, Hibiscus sabdariffa polyphenolic extract inhibits hyperglycemia, hyperlipidemia, and glycation-oxidative stress while improving insulin resistance. J. Agric. Food. Chem. 2011; 59: 9901-9909. https://doi.org/10.1021/jf2022379

26. Nafizah AH, Budin SB, Zaryantey AH, Mariati AR, Santhana RL, Osman M, Hanis MI, Jamaludin M, Aqueous calyxes extract of Roselle or Hibiscus sabdariffa Linn supplementation improves liver morphology in streptozotocin induced diabetic rats. Arab. J. Gastroenterol. 2017; 18: 13-20. https:// doi.org/10.1016/j.ajg.2017.02.001

27. Al-Qahtani AM, Hibiscus sabdariffa L. extract ameliorates the diabetic late complications: Cardioprotective and nephroprotective effect in streptozotocin-induced diabetic rats. Int. J. Green. Pharm. 2018; 11: S896. http://dx.doi.org/10.22377/ ijgp.v11i04.1424. 